\title{
Secretions of Chamberlinius hualienensis Wang (Polydesmida: Paradoxosomatidae) during the reproductive migration stage
}

\author{
Junsei Taira* and Kazuyo Arakaki \\ Okinawa Prefectural Institute of Health and Environment, Ozato-son, Okinawa 901-1202, Japan
}

(Received 18 February 2002; Accepted 19 August 2002)

\begin{abstract}
Six minor secretory compounds: phenol, $p$-cresol, guaiacol, methyl benzoate, benzaldehyde dimethyl acetal and creosol have been identified from a methanol extract of the millipede Chamberlinius hualienensis Wang at the 7th nymphal and adult stages of reproductive migration. These compounds, except for methyl benzoate, were detected for the first time from $C$. hualienensis. Almost all female nymphs contained greater amounts of the compounds than male nymphs. In females the amounts of methyl benzoate and guaiacol remarkably decreased with development of the nymphal stage. Although only a defensive role has been postulated for millipede secretions, such a quantitative change in secretory compounds at the reproductive migration stage suggests they may possibly have a significant physiological function related to reproduction and/or development.
\end{abstract}

Key words: Millipede, Chamberlinius hualienensis, reproductive migration, $p$-cresol, phenol

\section{INTRODUCTION}

The millipede Chamberlinius hualienensis Wang (yanbaru-tosaka-yasude in Japanese) belongs to Polydesmida, which is known to be distributed in Formosa. Its first migration from Formosa to Japan was recorded in Nakagusuku, Okinawa Island in November, 1983 (Higa and Kishimoto, 1987). Outbreak has been noted throughout the island, other islands of Okinawa Prefecture, and more recently in Kagoshima Prefecture, indicating a migration toward the north. When disturbed, millipedes commonly emit secretions with a nasty smell. This response is regarded as a defensive mechanism. Volatile compounds so far identified from various millipedes include hydrogen cyanide, benzaldehyde, mandelonitrile, guaiacol, benzoic acid, phenol, etc. (Eisner et al., 1978). When an outbreak occurs, they occasionally invade houses with a nasty smell causing headaches and unpleasant feelings for humans. Recently, two major components, benzaldehyde and mandelonitrile, have been detected from the secretions of adult $C$. hualienensis which were reared in a polyethylene bag with raw potato slices as a diet (Kikunaga et al., 1993; Noguchi et al., 1997a).

C. hualienensis migrates twice in its life cycle, once during the nymphal stage and once during the adult stage in the field. Autumn is a significant period for the reproductive activity in this life cycle and then many residents complain about the secretions of the millipede (Higa et al., 1992). However, the relationship between the life cycle and its secretions has not yet been clarified. A previous study demonstrated that the quantity of minor components of the millipede changes with developmental stage (Noguchi et al., 1997b). In this study we focused on examining the minor secretory components emitted from the millipede in the nymphal and adult stages during reproductive migration.

\section{MATERIALS AND METHODS}

The millipede $C$. hualienensis Wang at the 7th nymphal and adult stages was collected in Ozato, Okinawa on October 8, 2000. Weight and length of the individual millipedes were recorded. Sexual distinction was made by observing the presence (male) or absence (female) of gonads. The developmental stage was determined by counting the number of anamorphosis (Higa et al., 1992). The size of the millipedes were as follows: $22.5 \pm 0.83$ $\mathrm{mm}$ in length, weighing $96 \pm 12.9 \mathrm{mg}$ (mean $\pm \mathrm{SD}$, $n=5$ ) for 7 th nymphal male, $21.7 \pm 0.76 \mathrm{~mm}$ in

\footnotetext{
* To whom correspondence should be addressed at: E-mail: tairaj@yahoo.co.jp
} 
length, weighing $88 \pm 6.7 \mathrm{mg}$ (mean $\pm \mathrm{SD}, n=5$ ) for 7 th nymphal female, $30.3 \pm 2.63 \mathrm{~mm}$ in length, weighing $188 \pm 43.7 \mathrm{mg}$ (mean $\pm \mathrm{SD}, n=10$ ) for adult male and $29.8 \pm 1.33 \mathrm{~mm}$ in length, weighing 196士 $23.6 \mathrm{mg}$ (mean $\pm \mathrm{SD}, n=10)$ for adult female. There was no sexual difference in the body weight and length of millipedes.

Each millipede was soaked in methanol $(1 \mathrm{ml})$ for $1 \mathrm{~h}$ at room temperature. The extract was filtered using a centrifugal filter (Ultrafree-MC Centrifugal Filter Units, Millipore Co.) and then $10 \mu \mathrm{l}$ of anthracene- $d_{10}(5.3 \mathrm{M}$ in methanol $)$ was added to the supernatant as an internal standard to determine an accurate peak area. Gas chromatography and mass spectrometry (GC/MS, HP-6890, Hewlett Packard) using a DB-1 capillary column (Agilent Technologies, $320 \mu \mathrm{m}$ I.D. $\times 30 \mathrm{~m}$ length in 0.25 $\mu \mathrm{m}$ film thickness) was used for analysis of the secretory components under the following conditions: carrier gas, He; inlet, split-less mode; MS detector temperature, $230^{\circ} \mathrm{C}$ and column temperature, from $40^{\circ} \mathrm{C}$ to $240^{\circ} \mathrm{C}$ at $10^{\circ} \mathrm{C} / \mathrm{min}$ with an initial $5 \mathrm{~min}$ hold. Each component was identified by comparing its chromatographic retention time $\left(t_{\mathrm{R}}\right)$ and mass spectrum with an authentic standard (Tokyo Kasei Kogyo Co., Ltd.). The quantity of the secretory compounds was determined using a calibration curve of each authentic compound and the data were statistically treated with a $U$-test.

\section{RESULTS AND DISCUSSION}

A total ion chromatogram (TIC) was obtained from the methanol extract of a millipede as shown in Fig. 1. All major peaks in the TIC were expected to be phenolic or benzoic acid derivatives. The mass spectrum of peak A $\left(t_{\mathrm{R}} 5.31 \mathrm{~min}\right)$ gave a molecular ion $\left(\mathrm{M}^{+}\right)$at $m / z 94$ (base peak) and other mass fragment ions (relative intensity, \%) at $\mathrm{m} / \mathrm{z} 66$ $(29 \%)$ and 65 (26\%), which was suggestive of phenol. GC-MS peaks B to F showed the following molecular and characteristic mass fragment ions. Peak B ( $\left.t_{\mathrm{R}} 6.92 \mathrm{~min}\right): \mathrm{M}^{+}, m / z 108$ (83\%), 107 (base peak), $77(17 \%)$ and $51(5 \%)$. Peak C $\left(t_{\mathrm{R}} 6.99 \mathrm{~min}\right)$ : $\mathrm{M}^{+}, m / z 124$ (78\%), 109 (base peak), 81 (56\%) and $51(5 \%)$. Peak D ( $\left.t_{\mathrm{R}} 7.11 \mathrm{~min}\right): \mathrm{M}^{+}, m / z 136(31 \%)$, 105 (base peak), 77 (59\%) and 51 (23\%). Peak E $\left(t_{\mathrm{R}}\right.$ $7.51 \mathrm{~min}): \mathrm{M}^{+}, m / z 152$ (1\%), 121 (base peak), 105 (12\%), 91 (17\%), 77 (29\%) and 51 (11\%). Peak F $\left(t_{\mathrm{R}} 8.73 \mathrm{~min}\right): \mathrm{M}^{+}, m / z 138$ (95\%), 123 (base peak), $51(16 \%), 95(29 \%)$ and $77(15 \%)$. This mass spectral information combined with $t_{\mathrm{R}}$ established the

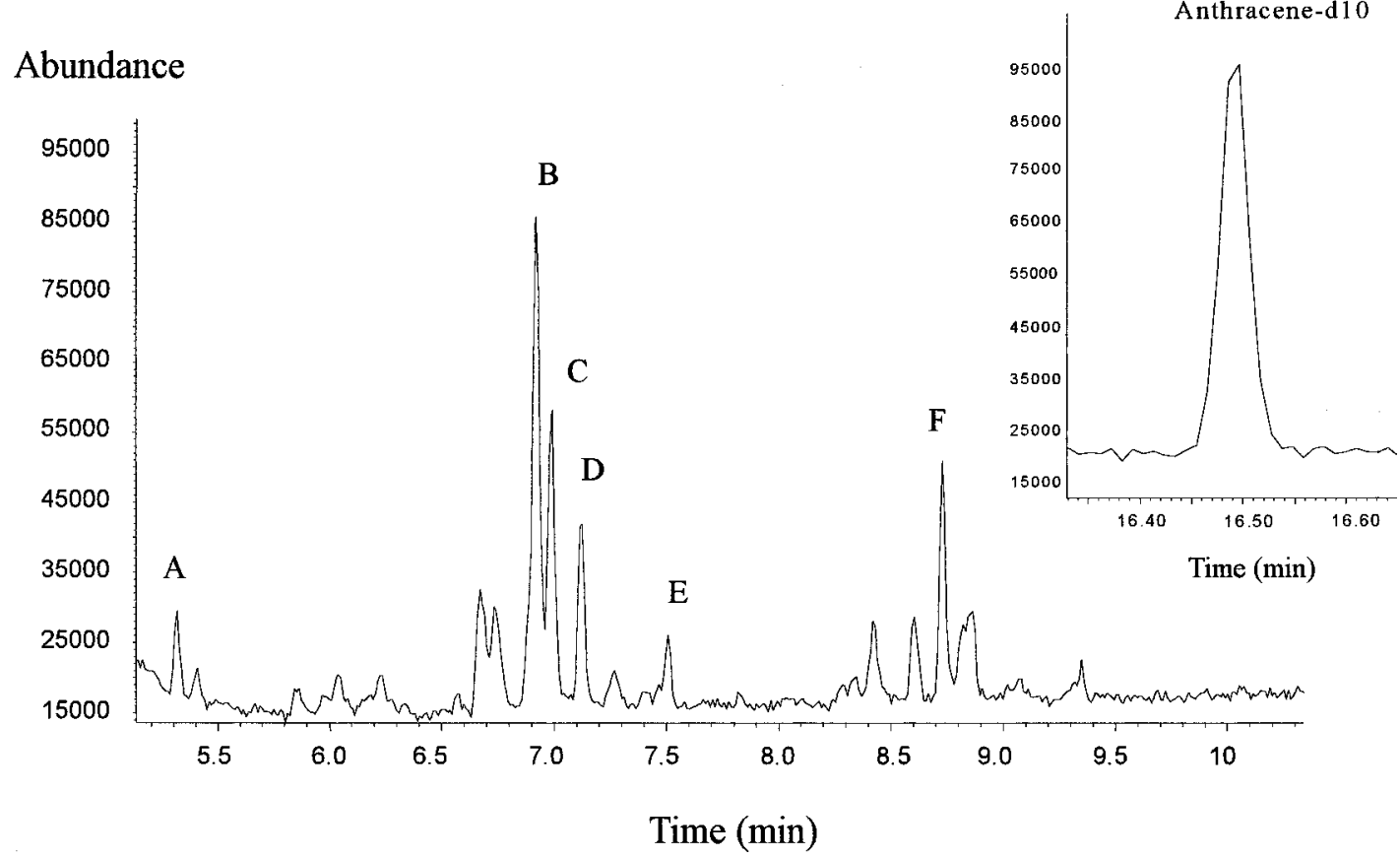

Fig. 1. Total ion chromatogram (TIC) of methanol extract of the millipede, C. hualienensis. Each peak was identified as follows: A, phenol; B, p-cresol; C, guaiacol; D, methyl benzoate; E, benzaldehyde dimethyl acetal and F, creosol. Inset indicates TIC of anthracene- $d_{10}$ as the internal standard. The details of the analytical conditions are described in the text. 
<smiles>Oc1ccccc1</smiles>

A<smiles>COC(=O)c1ccccc1</smiles>

D<smiles>Cc1ccc(O)cc1</smiles>

B<smiles>COC(OC)c1ccccc1</smiles>

E<smiles>COc1ccccc1O</smiles>

C<smiles>COc1cc(C)ccc1O</smiles>

F
Fig. 2. Chemical structures of components detected from methanol extract of $C$. hualienensis. A, phenol; B, p-cresol; C, guaiacol; D, methyl benzoate; E, benzaldehyde dimethyl acetal and $\mathrm{F}$, creosol.

identity of these compounds as $p$-cresol, guaiacol, methyl benzoate, benzaldehyde dimethyl acetal and creosol, respectively. Their chemical structures are depicted in Fig. 2. In this study, five components of phenol, $p$-cresol, guaiacol, benzaldehyde dimethyl acetal and creosol were detected for the first time in $C$. hualienensis. The constituents and their amounts in the individuals were variable depending on their habitat, suggesting that the environment affects the production of these secretory compounds (unpublished data). The other peaks in the TIC were also indicative of similar components from their mass fragment ions, but they have not yet been identified.

Figure 3 indicates the quantitative changes in the secretion of the nymphal and adult stages of the millipede. When the sexes were compared, almost all females at the nymphal stage contained greater amounts of these compounds than the males. A difference in the amount of phenol between the sexes was also observed in the adult millipedes. A quantitative change of phenol, which is a female-biased compound, was also similar to the adult of Nedyopus patrioticus patrioticus (Noguchi et al., 1997b). The amounts of methyl benzoate and guaiacol for the sexes indicated a significant reduction with development. On the other hand, there was no significant difference in the amounts of the compounds between the sexes of the millipede collected in De-

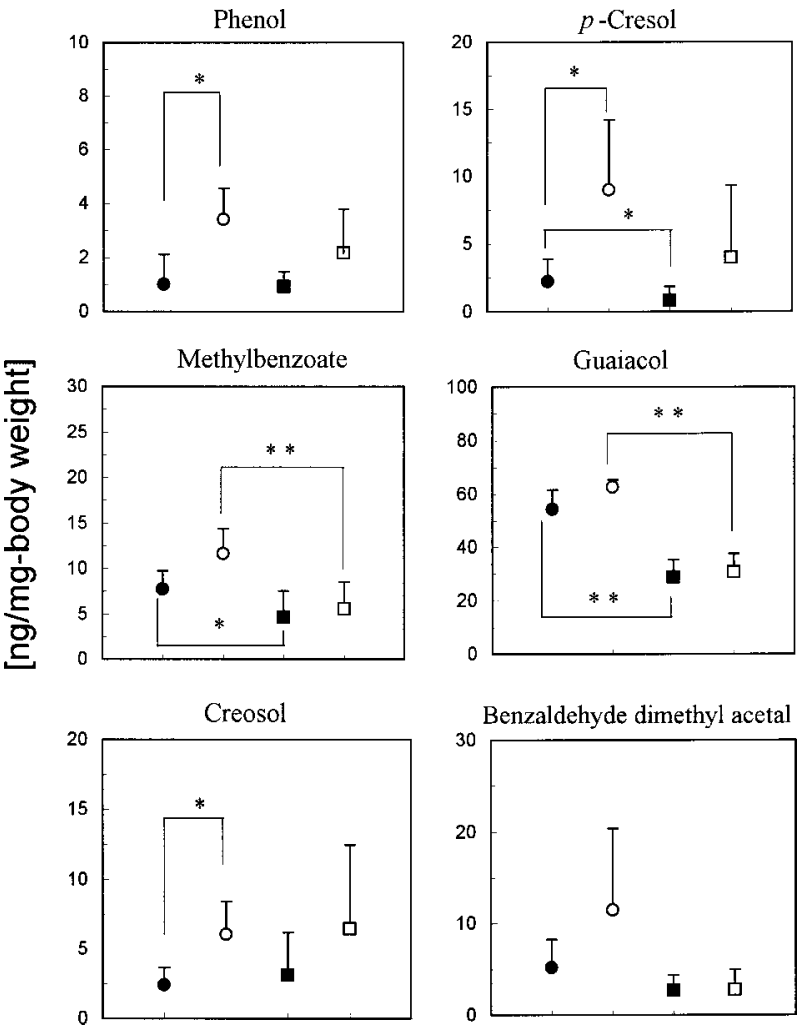

Fig. 3. Quantitative difference in change of secretory components due to the sexes and development. Nymph: male - female $\bigcirc$ and adult: male $\mathbf{\square}$; female $\square$. Data indicated as mean \pm SD and the significant differences are expressed as follows $* p<0.05$ and $* * p<0.01$.

cember (data not shown).

C. hualienensis migrates twice in its life cycle once during the nymphal stage and once during the adult stage in the field. Reproductive migration at nymphal and adult stages in the field takes place in October (Higa and Kishimoto, 1987). Interestingly, the female nymphs contained these secretions at high concentrations and some components were also observed to decrease with development. These results suggest that the secretions of the millipede have a significant physiological function related to reproduction and/or development.

\section{ACKNOWLEDGEMENTS}

We are grateful to Mses S. Iwanaga, Y. Higa and Mr. K. Shimoji for collecting the millipedes and their useful discussions (Okinawa Prefectural Institute of Health and Environment). We would like to thank Dr. T. Higa (Ryukyu University) for his helpful discussions on this paper. 


\section{REFERENCES}

Eisner, T., D. Alsop, K. Hicks and J. Meinwald (1978) Defensive secretions of millipedes. In Arthropod Venoms (S. Bettini ed.). Springer-Verlag, Berlin, pp. 41-72.

Higa, Y. and T. Kishimoto (1987) Unusual outbreak and control of the millipede, Chamberlinius hualienensis Wang in Okinawa. Annu. Rep. Okinawa Inst. Pub. Heal. 20: 6272 (in Japanese).

Higa, Y., T. Kishimoto and K. Nijima (1992) Seasonal fluctuation of the Chamberlinius hualienensis Wang (Diplopoda: Strongylosomidae) on Okinawa Island. Annu. Rep. Okinawa Inst. Pub. Heal. 26: 42-49 (in Japanese).

Kikunaga, T., H. Kinjo and M. Kuniyoshi (1993) Studies on the constituents of smells from some Okinawan local millipedes. Bull. Coll. Sci. Univ. Ryukyus 56: 91-112 (in Japanese with English summary).

Noguchi, S., N. Mori, Y. Higa and Y. Kuwahara (1997a) Identification of Mandelonitrile as a major secretory compound from Chamberlinius hualienensis Wang (Polydesmida: Paradoxosomatidae). Jpn. J. Environ. Entomol. Zool. 8: 208-214.

Noguchi, S., N. Mori, Y. Higa and Y. Kuwahara (1997b) Identification of Nedyopus patrioticus patrioticus (Attems, 1898) (Polydesmida: Paradoxosomatidae) secretions as possible defense substances. Appl. Entomol. Zool. 32: 447-452. 